CONCISE REPORT

\title{
Pituitary function in patients with newly diagnosed untreated systemic lupus erythematosus
}

\author{
M D Köller, E Templ, M Riedl, M Clodi, O Wagner, J S Smolen, A Luger
}

Ann Rheum Dis 2004;63:1677-1680. doi: 10.1136/ard.2003.018325

\begin{abstract}
Objectives: To determine whether hormonal dysfunction involving the hypothalamic-pituitary-adrenal (HPA) axis, prolactin (PRL) secretion, and sex hormone status contribute to development of systemic lupus erythematosus (SLE).

Methods: 11 patients with SLE and 9 healthy controls were tested for their total anterior pituitary gland reserve by simultaneous injection of corticotropin-, growth hormone$(G H)$, thyrotropin-, and gonadotropin-releasing hormone $(\mathrm{GnRH})$. Serum concentrations of adrenocorticotropin (ACTH), cortisol, GH, thyroid stimulating hormone (TSH), PRL, luteinising hormone (LH), and follicle stimulating hormone (FSH) were measured at baseline and after injection. Baseline values of oestradiol, testosterone, and thyroxine were determined.

Results: Basal and stimulated serum concentrations of $\mathrm{ACTH}$, cortisol, GH, and PRL were similar in both groups. In contrast, despite similar basal thyroxine levels the TSH response to TRH was significantly higher in patients than in controls. LH and FSH levels in premenopausal female patients of both groups were identical. In contrast, two of the three male patients were hypogonadal without compensatory increases of basal LH and FSH levels, but they retained excessive stimulatory capacity in response to $\mathrm{GnRH}$.

Conclusion: No significant alteration of the HPA axis was found in patients with SLE, which is inadequate in view of the continuing inflammation. GH and PRL secretion were normal. The pituitary-thyroid and pituitary-gonadal axes were affected in patients with newly diagnosed, untreated SLE.
\end{abstract}

S tudies show that the neuroendocrine system influences immunity and vice versa. Inflammation is accompanied by raised levels of cytokines like interleukin (IL)6 or tumour necrosis factor (TNF) $\alpha$ that can activate the hypothalamic-pituitary-adrenal (HPA) axis. ${ }^{1}$

Evidence exists showing a link between sex hormones and the development of autoimmune diseases. The prevalence of systemic lupus erythematosus (SLE) is greatest in young women. This is one of the most obvious clinical observations in both, humans and animals, suggesting a causal role for sex steroids in the pathogenesis of SLE. Prolactin (PRL) influences lymphocyte function by inducing IL2 receptor expression. Furthermore, exogenic gonadotropin-releasing hormone $(\mathrm{GnRH})$ increases disease activity in lupus prone mice.

Most studies elucidating the interaction of the endocrine network and autoimmunity in SLE have been performed in patients with longlasting disease and who therefore have a history of glucocorticoid intake. This may limit the interpretation of those results. Therefore, we investigated the total anterior pituitary reserve in patients with SLE before the initiation of glucocorticoid or immunosuppressive treatment.

\section{PATIENTS AND METHODS}

\section{Patients and healthy controls}

The protocol was approved by the local ethics committee. Written consent was obtained from all participants. Eleven patients with SLE according to the revised, updated criteria of the American College of Rheumatology were included: eight women (two of them postmenopausal) and three men with a mean (SEM) age of 34.1 (4.9) years. Disease activity was evaluated by European Consensus Lupus Activity Measurement (ECLAM) score and SLE Disease Activity Index (SLEDAI). None of the patients had ever been treated with corticosteroids or immunosuppressive agents. Ten patients had mild to moderate disease, one patient had high activity with lupus nephritis: mean (SEM) ECLAM score 3.8 (0.6), mean (SEM) SLEDAI 9.3 (1.8). Table 1 gives the demographic data.

Seven women (two of them postmenopausal) and two men with a mean (SEM) age of 38.3 (4.1) years served as healthy controls (HC).

\section{Stimulation test and hormone assay}

We performed a combined test for total anterior pituitary gland reserve with all hypothalamic releasing hormones. ${ }^{2}$ All participants had refrained from food and drink for at least 4 hours before testing. Baseline blood samples were taken after a 30 minute rest at $0400 \mathrm{pm}$. Then releasing hormones were injected simultaneously as a bolus: $100 \mu \mathrm{g}$ corticotropin-releasing hormone (CRH; Ferring, Cologne, FRG), $100 \mu \mathrm{g}$ growth hormone-releasing hormone (GHRH; Ferring, Cologne, Germany), $200 \mu \mathrm{g}$ thyrotropin-releasing hormone (TRH; Behring, Vienna, Austria), and $100 \mu \mathrm{g}$ GnRH (Aventis, Frankfurt, Germany). Peripheral blood levels of adrenocorticotropin (ACTH), cortisol, GH, thyroid stimulating hormone (TSH), PRL, as well as luteinising hormone (LH) and follicle stimulating hormone (FSH) were measured at $(-15), 0,15$, $30,60,90$, and 120 minutes. Additionally, we determined baseline values for oestradiol, testosterone, and total thyroxine $\left(\mathrm{T}_{4}\right)$. Commercially available radioimmunoassays were used to measure oestradiol (coefficient of variation (CV) $\leqslant 8 \%$ ), testosterone ( $\mathrm{CV} \leqslant 6 \%)$, GH ( $\mathrm{CV} \leqslant 6 \%$; all purchased from Diagnostic Products Corporation, Los Angeles, USA), and TSH ( CV $\leqslant 5 \%$; Behringwerke AG, Marburg, FRG). ACTH was determined by an immunoradiometric assay ( $C V \leqslant 6 \%$; Cis Bio International, Gif-sur-Yvette Cedex, France), cortisol $(\mathrm{CV} \leqslant 9 \%)$, FSH $(\mathrm{CV} \leqslant 3 \%)$, PRL $(\mathrm{CV} \leqslant 8 \%), \mathrm{T}_{4}(\mathrm{CV} \leqslant 3 \%)$ by

\footnotetext{
Abbreviations: $\mathrm{ACTH}$, adrenocorticotropin; $\mathrm{CRH}$, corticotropinreleasing hormone; CV, coefficient of variation; DHEA dehydroepiandrosterone; ECLAM, European Consensus Lupus Activity Measurement; $\mathrm{FSH}$, follicle stimulating hormone; $\mathrm{GH}$, growth hormone; $\mathrm{GHRH}$, growth hormone-releasing hormone; $\mathrm{GnRH}$, gonadotropinreleasing hormone; $\mathrm{HC}$, healthy controls; HPA, hypothalamic-pituitaryadrenal; IL, interleukin; LH, luteinising hormone; PRL, prolactin; RA, rheumatoid arthritis; SLE, systemic lupus erythematosus; SLEDAl, SLE Disease Activity Index; $T_{4}$, thyroxine; TNF, tumour necrosis factor; TRH, thyrotropin-releasing hormone; TSH, thyroid stimulating hormone
} 
Table 1 Patient characteristics

\begin{tabular}{|c|c|c|c|c|c|c|c|c|c|c|c|c|c|}
\hline Sex & Age & ECLAM & SLEDAI & ANA & dsDNA Ab & C3 & C4 & $\mathrm{CH}_{50}$ & ESR & CRP & $T_{4}$ & $\mathrm{Oe}_{2}$ & Testosterone \\
\hline $\mathrm{F}$ & 25 & 2 & 6 & $1 / 5120$ & 18.6 & 54.7 & 18.6 & 81.2 & 67 & 8 & 82.0 & 10.0 & ND \\
\hline $\mathrm{F}$ & 20 & 2 & 6 & $1 / 1280$ & 58.0 & 56.6 & 5.8 & 76.1 & 24 & 5 & 84.0 & 21.0 & ND \\
\hline $\mathrm{F}$ & 23 & 3 & 5 & $1 / 160$ & 84.4 & 37.7 & 15.3 & 37.8 & 36 & 5 & 72.0 & 10.0 & ND \\
\hline $\mathrm{F}$ & 26 & 5 & 12 & $1 / 5120$ & 6.2 & 70.8 & 29.8 & 87.9 & 25 & 4. & 80.0 & 31.0 & ND \\
\hline $\mathrm{F}$ & 26 & 5 & 11 & $1 / 5120$ & 155.0 & 40.0 & 6.6 & 55.6 & 70 & 16 & 81.0 & 41.0 & ND \\
\hline $\mathrm{F}$ & 49 & 5 & 12 & $1 / 2560$ & 43.0 & 53.5 & 9.0 & 100.2 & 85 & 5 & 89.0 & 20.0 & ND \\
\hline $\mathrm{F}$ & 23 & 2 & 6 & $1 / 640$ & 59.0 & 108.0 & 18.7 & 155.0 & 45 & 16 & 104.0 & 10.0 & ND \\
\hline $\mathrm{F}$ & 50 & 4 & 8 & $1 / 160$ & 73.1 & 39.0 & 8.2 & 115.1 & 68 & 14 & 107.0 & 12.0 & ND \\
\hline$M$ & 34 & 2 & 7 & $1 / 80$ & 84.7 & 148.0 & 42.2 & 144.0 & 21 & 63 & 90.0 & ND & 3.89 \\
\hline$M$ & 27 & 9 & 25 & $1 / 2560$ & 737.0 & 13.5 & 6.6 & 31.8 & 93 & 9 & 78.0 & ND & 1.59 \\
\hline$M$ & 72 & 3 & 4 & $1 / 5120$ & 101.0 & 80.2 & 15.2 & 93.7 & 70 & 78 & 102.0 & ND & 1.89 \\
\hline
\end{tabular}

Sex (F, female; M, male); age (years); ECLAM, European Consensus of Lupus Activity Measurement; SLEDAl, Systemic Lupus Erythematosus Disease Activity Index; ANA, antinuclear antibody titre (tested on Hep-2); dsDNA Ab, antibodies against dsDNA (measured by radioimmunoassay; $\mathrm{U} / \mathrm{ml}$; normal range $<7.0$ ); $\mathrm{C} 3$, $\mathrm{C} 4$, complement factors (C3, normal range $50-90 \mathrm{mg} / \mathrm{ml} ; \mathrm{C} 4$, normal range 10-40 mg/ml); $\mathrm{CH}_{50}$, total haemolytic complement activity (normal range $50-150 \%$ ); ESR, erythrocyte sedimentation rate $\left(\mathrm{mm} / 1 \mathrm{st}\right.$ h); CRP, C reactive protein (normal range $<5 \mathrm{mg} / \mathrm{l}$ ), $\mathrm{T}_{4}$, thyroxin (normal range $50-120 \mathrm{ng} / \mathrm{ml}$ ); Oe 2 , oestradiol (normal range 22-232 pg/ml; ND, not determined in men); testosterone (normal range 2.7-10.7 ng/ml; ND, not determined in women).

enzyme immunological tests (all from Boehringer Mannheim GmbH, Mannheim, FRG), and LH by time resolved fluoroimmunoassay (CV $\leqslant 5 \%$; Wallac, Turku, Finland).

\section{Statistical analysis}

Data in the figures are expressed as mean (SEM). Statistical distribution was analysed by Kolmogorov-Smirnov test and values were compared using an unpaired $t$ test. A p value $<0.05$ was considered significant. All statistics were calculated with GraphPad Prism 3.0.

\section{RESULTS}

After injection of CRH a significant increase of ACTH was detected, which tended to be higher in patients with SLE (peak levels after 30 minutes: SLE 65.9 (25.9) pg/ml $v$ HC $46.3(9.9) \mathrm{pg} / \mathrm{ml}$ ). However, differences were not statistically significant. Though basal cortisol levels tended to be higher in patients than in HC $(290$ (40) nmol/l $v 220$ (30) nmol/l), cortisol release was comparable with maximum concentrations 60 minutes after stimulation (SLE 500 (40) nmol/l $v$ HC 510 (30) $\mathrm{nmol} / \mathrm{l}$ ).

Basal $\mathrm{T}_{4}$ levels $(88.1(3.5) \mathrm{ng} / \mathrm{ml}$ in patients with SLE $v 78.0$ (4.2) $\mathrm{ng} / \mathrm{ml}$ in controls, NS) were comparable. After TRH injection significantly higher TSH levels were measured in patients than in controls $(\mathrm{p}<0.05$; fig 1$)$. In contrast, basal (SLE $11.1 \quad(1.2) \mathrm{ng} / \mathrm{ml} \quad v$ HC 9.8 (1.8) ng/ml) and $\mathrm{TRH}$ stimulated PRL concentrations (maximum after 15 minutes; SLE $100.5 \quad(14.8) \mathrm{ng} / \mathrm{ml} \quad v \quad \mathrm{HC} \quad 110.4 \quad(19.5) \mathrm{ng} / \mathrm{ml})$ were similar.

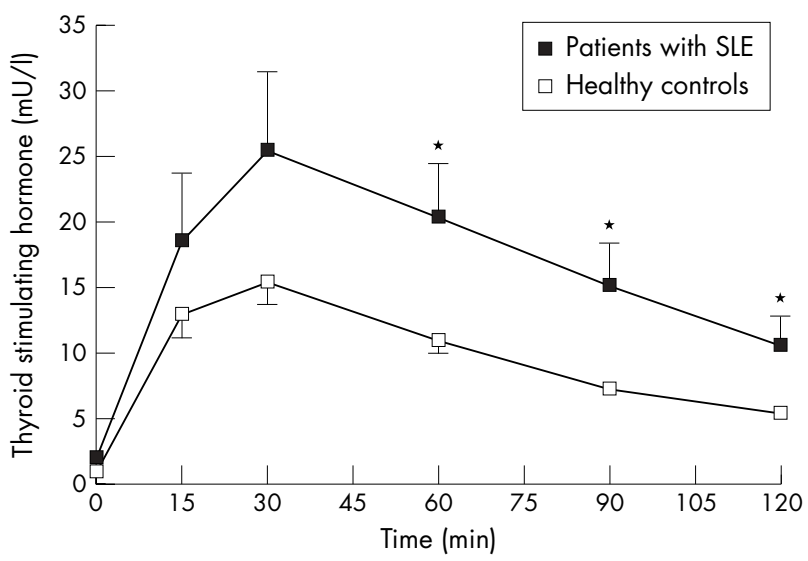

Figure 1 Thyroid stimulating hormone serum concentrations before and after pituitary stimulation by thyrotropin-releasing hormone (TRH) in patients with SLE and healthy controls.
At baseline and after GHRH injection, GH levels were almost identical in both groups (basal: SLE $2.1(0.6) \mathrm{ng} / \mathrm{ml} v$ HC 2.1 (0.9) ng/ml; 30 minute peak: SLE 20.5 (4.2) ng/ml $v$ HC 24.0 (6.3) ng/ml).

After GnRH injection LH and FSH levels were virtually identical in premenopausal female patients compared with controls. Interestingly, two of the three male patients were clearly hypogonadal with low testosterone serum concentrations (table 1) but (inadequately) normal basal gonadotropin
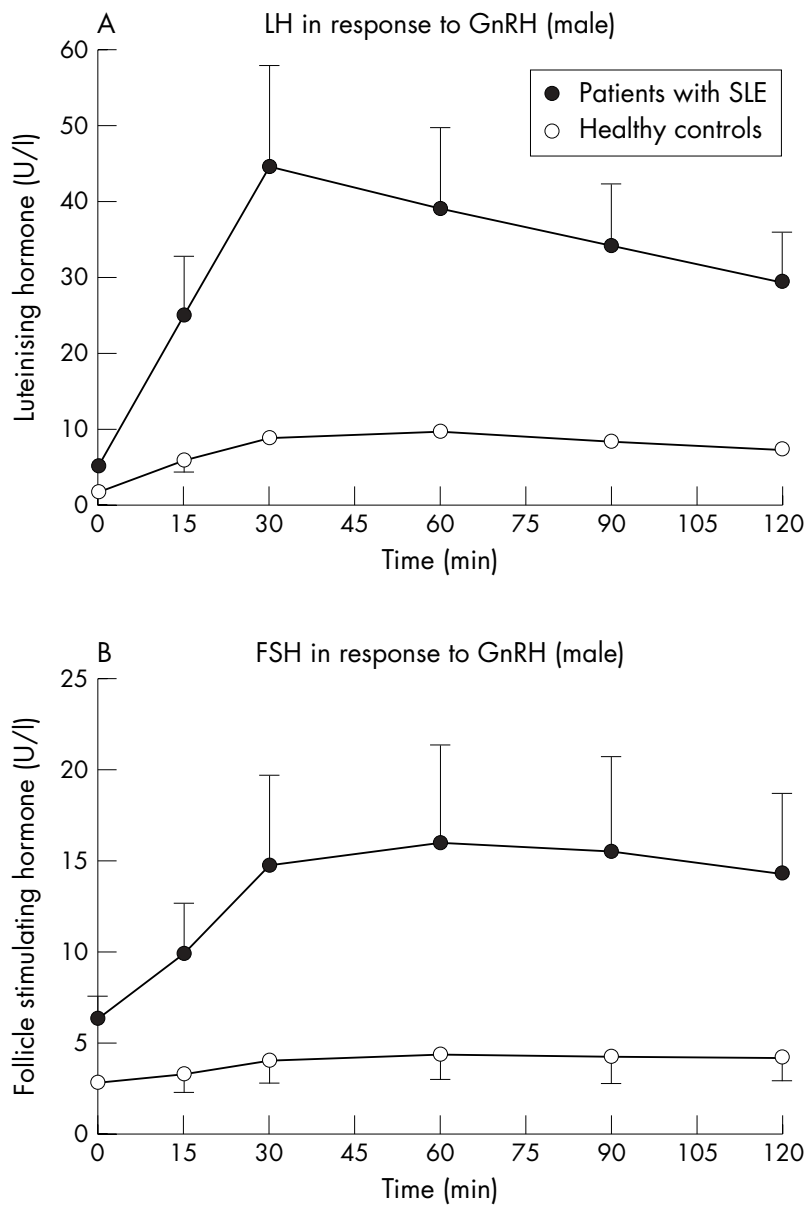

Figure 2 Serum levels of (A) luteinising hormone (LH) and (B) follicle stimulating hormone (FSH) before and after pituitary stimulation by gonadotropin-releasing hormone $(\mathrm{GnRH})$ in male patients with SLE and healthy controls. 
concentrations. However, excessive stimulatory capacity in response to GnRH was retained and even tended to be higher (fig 2A). Owing to the limited number of men tested, the difference failed significance (fig 2B).

Within the SLE group we found no significant differences between female or male patients in their pituitary response after stimulation.

\section{DISCUSSION}

We analysed the overall pituitary end organ function in patients with newly diagnosed SLE who had not received glucocorticoid or immunosuppressive treatment.

Former reports have suggested that SLE is associated with dysfunction of the HPA axis and PRL secretion. Zietz et al found an altered function of the HPA axis in moderately active SLE; although baseline and stimulated serum androstenedione, cortisol, and dehydroepiandrosterone (DHEA) were lower in patients with SLE, plasma levels of ACTH were normal. This was not expected in patients receiving prednisolone. Furthermore, in relation to the level of IL6 or TNF, cortisol was clearly low compared with controls. ${ }^{3}$ In contrast, we did not find significant alterations of the HPA axis in patients with SLE who had not been treated. In the presence of an active autoimmune disease the failure to activate the HPA axis might be considered as an inadequate response to inflammatory stress. This is in line with data which show that levels of ACTH and cortisol are relatively low in relation to levels of IL6 and TNF in patients with untreated early rheumatoid arthritis (RA). ${ }^{4}$

Previous studies have also reported abnormal thyroid function tests in patients with SLE without known thyroid disease. SLE may be associated with autoimmune thyroiditis and a higher prevalence of hypothyroidism than the normal population, ${ }^{5}$ though reports are conflicting. Patients with SLE tested in our study had normal basal $\mathrm{T}_{4}$ and TSH levels. However, compared with controls, stimulated TSH levels were significantly higher, suggesting latent hypothyroidism among patients. Unfortunately, we did not test autoantibodies against thyroid antigens.

GH has stimulatory effects on different immune functions. In juvenile RA abnormally low circadian secretion of GH has been measured. Furthermore, we have previously demonstrated a blunted GH response to GHRH in patients with RA. ${ }^{2}$ In contrast, no alteration of GH release could be detected here in patients with untreated SLE.

In vitro, PRL has been shown to augment lymphocyte proliferation. Moreover, raised serum PRL concentrations and PRL/cortisol ratio have been reported to be associated with autoimmunity in SLE. ${ }^{6}$ However, patients with prolactinomas have no signs of lymphocyte activation ex vivo. ${ }^{7}$ Here, among patients with SLE, basal and stimulated PRL levels were comparable with those of controls.

Mok et al concluded that ovarian failure with hypooestrogenaemia is protective against lupus flares. ${ }^{8}$ Furthermore, in lupus prone mice tamoxifen-an oestrogen antagonist—had beneficial effects, ${ }^{9}$ although a clinical trial showed no benefit of tamoxifen in women with SLE. ${ }^{10}$ Therefore it seems of interest that in our study no difference in basal sex hormone levels or in gonadotropin response to GnRH was found in premenopausal female patients compared with HC.

Findings obtained among male patients with SLE are of particular interest: two of the three men were clearly hypogonadal. Although the gonadotropin response to a supraphysiological GnRH dose was significantly enhanced, the lack of compensatory rise of basal LH concentrations suggests additional pituitary dysfunction. Together these data suggest profound primary hypogonadism but only mild pituitary dysfunction in association with SLE.
In another study a small cohort of four male patients with normal sexual activity and genital function showed decreased fertility based on sperm abnormalities, ${ }^{11}$ but these patients were receiving treatment with cytotoxic drugs. In contrast our patients had not received any previous immunosuppressive treatment. The finding of low basal and stimulated DHEA levels in female patients with $\mathrm{RA}^{12}$ as well as in patients with SLE, ${ }^{3}$ and the beneficial effect of DHEA treatment in patients with SLE, ${ }^{13}{ }^{14}$ support the view that not only oestrogens but also androgens may participate in the pathogenesis of autoimmune diseases. Former studies have suggested that testosterone may directly suppress anti-DNA antibody production in peripheral blood mononuclear cells from patients with SLE by inhibiting B cell function. ${ }^{15}$ The report of significant clinical improvement of SLE symptoms during testosterone treatment provides further evidence for a role of androgens in SLE.

In summary, we found a differential state of pituitary end organ function in untreated SLE. The HPA axis appeared to be unaffected, which seems inadequate in view of continuing inflammation. In contrast, the pituitary-thyroid and pituitary-gonadal axes are clearly disturbed. The primary defect appears mainly in the peripheral endocrine organs, with an additional mild pituitary dysfunction. Thus, endocrine abnormalities are present among patients with SLE at (or before) the onset of disease.

\section{Authors' affiliations}

M D Köller, J S Smolen, Clinic for Internal Medicine III, Department of Rheumatology, University of Vienna, Austria

E Templ, M Riedl, M Clodi, A Luger, Clinic for Internal Medicine III, Department of Endocrinology and Metabolism, University of Vienna, Austria

O Wagner, Institute of Clinical Chemistry and Laboratory Diagnostic, University of Vienna, Austria

Correspondence to: Dr M D Köller, Department of Internal Medicine III, Division of Rheumatology, General Hospital, Währinger Gürtel 18-20, A-1090 Vienna, Austria; Marcus.Koeller@meduniwien.ac.at

Accepted 10 March 2004

Published Online First 13 April 2004

\section{REFERENCES}

1 Mastorakos G, Chrousos GP, Weber JS. Recombinant interleukin-6 activates the hypothalamic-pituitary-adrenal axis in humans. J Clin Endocrinol Metab 1993;77:1690-4

2 Templ E, Koeller M, Riedl M, Wagner O, Graninger W, Luger A. Anterior pituitary function in patients with newly diagnosed rheumatoid arthritis. Br J Rheumatol 1996;35:350-6.

3 Zietz B, Reber T, Oertel M, Gluck T, Scholmerich J, Straub RH. Altered function of the hypothalamic stress axes in patients with moderately active systemic lupus erythematosus. II. Dissociation between androstenedione, cortisol, or dehydroepiandrosterone and interleukin 6 or tumor necrosis factor. J Rheumatol 2000;27:911-18.

4 Straub RH, Paimela L, Peltomaa R, Scholmerich J, Leirisalo-Repo M. Inadequately low serum levels of steroid hormones in relation to interleukin- 6 and tumor necrosis factor in untreated patients with early rheumatoid arthritis and reactive arthritis. Arthritis Rheum 2002;46:654-62.

5 Pyne D, Isenberg DA. Autoimmune thyroid disease in systemic lupus erythematosus. Ann Rheum Dis 2002;61:70-2.

6 Neidhart M. Elevated serum prolactin or elevated prolactin/cortisol ratio are associated with autoimmune processes in systemic lupus erythematosus and other connective tissue diseases. J Rheumatol 1996;23:476-81.

7 Koller M, Kotzmann H, Clodi M, Riedl M, Luger A. Effect of elevated serum prolactin concentrations on the immunophenotype of human lymphocytes, mitogen-induced proliferation and phagocytic activity of polymorphonuclear cells. Eur J Clin Invest 1997;27:662-66.

8 Mok CC, Wong RW, Lau CS. Ovarian failure and flares of systemic lupus erythematosus. Arthritis Rheum 1999;42:1274-80.

9 Sthoeger ZM, Zinger H, Mozes E. Beneficial effects of the anti-oestrogen tamoxifen on systemic lupus erythematosus of (NZBxNZW)Fl female mice are associated with specific reduction of IgG3 autoantibodies. Ann Rheum Dis 2003;62:341-6. 
10 Sturgess AD, Evans DT, Mackay IR, Riglar A. Effects of the oestrogen antagonist tamoxifen on disease indices in systemic lupus erythematosus. J Clin Lab Immunol 1984;13:11-14.

11 Silva CA, Hallak J, Pasqualotto FF, Barba MF, Saito MI, Kiss MH. Gonadal function in male adolescents and young males with juvenile onset systemic lupus erythematosus. J Rheumatol 2002;29:2000-5.

12 Cutolo M, Foppiani L, Prete C, Ballarino P, Sulli A, Villaggio B, et al. Hypothalamic-pituitary-adrenocortical axis function in premenopausal women with rheumatoid arthritis not treated with glucocorticoids. J Rheumatol 1999;26:282-8.
13 van Vollenhoven RF, Park JL, Genovese MC, West JP, McGuire JL. A doubleblind, placebo-controlled, clinical trial of dehydroepiandrosterone in severe systemic lupus erythematosus. Lupus 1999;8:181-7.

14 Petri MA, Lahita RG, van Vollenhoven RF, Merrill JT, Schiff M, Ginzler EM, et al. Effects of prasterone on corticosteroid requirements of women with systemic lupus erythematosus: a double-blind, randomized, placebocontrolled trial. Arthritis Rheum 2002;46:1820-9.

15 Kanda N, Tsuchida T, Tamaki K. Testosterone suppresses anti-DNA antibody production in peripheral blood mononuclear cells from patients with systemic upus erythematosus. Arthritis Rheum 1997;40:1703-11.

\section{Get published within days of acceptance with ARD}

We are delighted to announce that the Annals of the Rheumatic Diseases launched a "publish ahead of print" programme in February 2004. Selected papers are fast tracked and published online months before they appear in the print journal.

Papers of major significance to the international rheumatology community are published within days of acceptance. The first published article is the raw accepted manuscript; edited and typeset versions are also published as soon as they are available.

In addition to being available on ARD Online, the publish ahead of print articles are searchable through PubMed/ Medline-establishing primacy for your work. They are linked from the ARD Online home page.

$A R D^{\prime}$ 's publish ahead of print programme is unique among the major rheumatology journals - to take advantage of this service submit your papers to Annals of the Rheumatic Diseases using our online submission and review system Bench>Press (http://submit-ard. bmijournals.com). For further information contact ARD@bmigroup.com. 